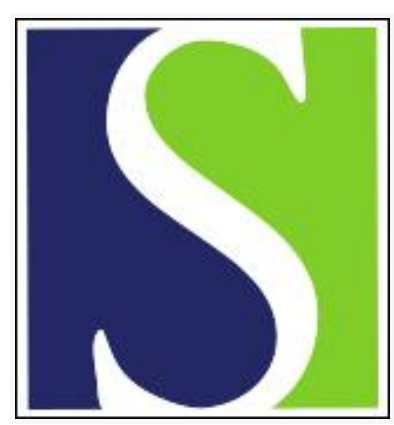

Scand J Work Environ Health 2021;47(3):200-207

https://doi.org/10.5271/sjweh.3933

Published online: 17 Nov 2020, Issue date: 01 Apr 2021

Effect of long work hours and shift work on high-sensitivity C-reactive protein levels among Korean workers by Lee W, Kang S-K, Choi W-J

There is an interaction effect of long work hours and shift work on the elevation of high-sensitivity C-reactive protein (hSCRP). Work conditions may play a key role in the elevation of systemic inflammation.

Affiliation: Department of Occupational and Environmental Medicine, Gil Medical Center, Gachon University College of Medicine, Incheon, Republic of Korea. wjchoi@gachon.ac.kr

Refers to the following text of the Journal: 2010;36(2):96-108

The following article refers to this text: 2021;47(8):565-581

Key terms: C-reactive protein; cardiovascular disease; hsCRP; inflammation; KNHANES; Korea; Korean worker; long work hour; shift worker; work hour; working hour

This article in PubMed: www.ncbi.nlm.nih.gov/pubmed/33201246 


\title{
Effect of long work hours and shift work on high-sensitivity C-reactive protein levels among Korean workers
}

\author{
by Wanhyung Lee, MD, ${ }^{1}$ Seong-Kyu Kang, MD, ${ }^{1}$ Won-Jun Choi,MD ${ }^{1}$
}

\begin{abstract}
Lee W, Kang S-K, Choi W-J. Effect of long work hours and shift work on high-sensitivity C-reactive protein levels among Korean workers. Scand J Work Environ Health. 2021;47(3):200-207. doi:10.5271/sjweh.3933
\end{abstract}

\begin{abstract}
Objective We aimed to investigate the association between low-grade inflammation as indicated by highsensitivity C-reactive protein (hsCRP) level and organizational factors, such as work hours and shift work.

Methods We evaluated 7470 young and middle-aged workers who participated in the Korea National Health and Nutrition Examination Surveys from 2015-2018. Work hours were determined from self-reported questionnaires. Shift work was defined as a non-daytime fixed work schedule. An interaction effect between shift work and long work hours on the hsCRP level was estimated using relative excess risk due to interaction (RERI) and attributable proportion (AP) with $95 \%$ confidence intervals (CI).
\end{abstract}

Results Increased hsCRP levels were prevalent in $25.2 \%$ of the study population. There was a significant association between long work hours and increased hsCRP, especially among middle-aged men [odds ratio (OR) 1.50 (95\% CI 1.20-1.87) for moderately increased hsCRP and OR 1.62 (95\% CI 1.14-2.30) for highly increased hsCRP]. There was a significant interaction effect between long work hours and shift work on increased hsCRP among middle-aged workers. The RERI were 0.03 (95\% CI 0.02-0.04) and 0.56 (95\% CI 0.45-0.68) among middle-aged men and women, respectively. The AP were 0.02 (95\% CI $0.01-0.03)$ and $0.36(95 \% \mathrm{CI} 0.31-0.40)$ among middle-aged men and women, respectively.

Conclusions There was no significant association between shift work and the level of hsCRP. Long work hours were related to low-grade inflammatory processes, but only in middle-aged workers. There was an interaction effect between long work hours and shift work for increased hsCRP, especially in middle-aged women.

Key terms cardiovascular disease; hsCRP; inflammation; KNHANES; Korea; shift worker; working hour.

Although an adequate systemic inflammatory response is essential for successful recovery from injuries and infections, chronic low-grade or subclinical inflammation may lead to health problems (1). Several reports have described the relationship between inflammation and cardiovascular diseases (CVD) (2), arrhythmias (3), stroke (4) and neurological disorders (5). A complex inflammatory response mediates the pathogenesis of atherosclerosis, which is the underlying pathology of CVD (6). Among numerous biomarkers related to systemic inflammation, the high-sensitivity C-reactive protein (hsCRP) level, which is easily accessible in the clinical setting (7), is associated with the risk of CVD and other vascular pathologic changes $(8,9)$.
Occupational factors, such as working hours and shift work, may be associated with various health problems $(10,11)$. The disruption of the circadian rhythm, exposure to artificial light, psychological stress, and other social and lifestyle factors associated with work patterns can promote chronic systematic inflammation (12-14). Factors associated with organizational work may also influence systemic inflammation. In a recent review, Virtanen \& Kivimäki (15) concluded that long working hours were a risk factor for CVD. The plausible pathways leading from shift work to CVD are related to psychosocial, behavioral, and physiological mechanisms (16). Shift work may cause physiological stresses, such as inflammation, blood coagulation, and altered cardiac

1 Department of Occupational and Environmental Medicine, Gil Medical Center, Gachon University College of Medicine, Incheon, Republic of Korea.

Correspondence to: Won-Jun Choi, Gachon University College of Medicine, 38-13, Dokjeom-ro 3beon-gil, Namdong-gu, Incheon, Republic of Korea. [E-mail: wjchoi@gachon.ac.kr] 
autonomic functions, which are related to atherosclerotic changes. Puttonen et al (17) reported that irregular working hours, such as 2- and 3-shift work schedules, were associated with an increased risk of inflammation among airline employees. Results of other studies indicate that shift work is associated with elevated hsCRP levels among female workers (18) and a higher prevalence of hypertension among male workers with elevated serum ferritin levels (19). However, information on the interactive effects of work-related factors, such as long working hours and shift work, on systemic inflammation in the working population is still scarce.

Thus, this study aimed to investigate the association between hsCRP and organizational factors such as working hours and shift work in a representative sample of Korean workers.

\section{Methods}

\section{Study design and data collection}

We used data from the Korea National Health and Nutrition Examination Surveys (KNHANES), 2015-2018, that comprise a series of nationally representative population-based surveys on the health and nutritional status of Korean citizens conducted by the Korea Centers for Disease Control and Prevention. The KNHANES were based on self-questionnaires that gather information on different aspects such as demographics, socioeconomic status, dietary habits, and medical history. The surveys were conducted by a trained interviewers' assistant. Blood and urine sampling and anthropometric examination are also performed by trained professionals either at the home of respondents or in mobile examination centers (20). All KNHANES data are publicly available at the KNHANES website (http://knhanes.cdc.go.kr).

The participants of the KNHANES are identified annually through systematic sampling of Korean citizens using multistage clusters based on age, sex, and household registries. A total of 31649 participants were included in the 2015-2018 KNHANES (7380 in 2015; 8150 in 2016; 8127 in 2017; and 7992 in 2018).

The present study evaluated young and middleaged workers. We excluded 22030 individuals of the non-working population, 1649 individuals aged $<20$ or $>59$ years, and 500 individuals with missing data or who refused to share data. In total, 7470 participants were included in the analysis. The participant inclusion flowchart is shown in figure 1 .

\section{Shift work and long work hours}

Shift work was defined as a non-daytime fixed work

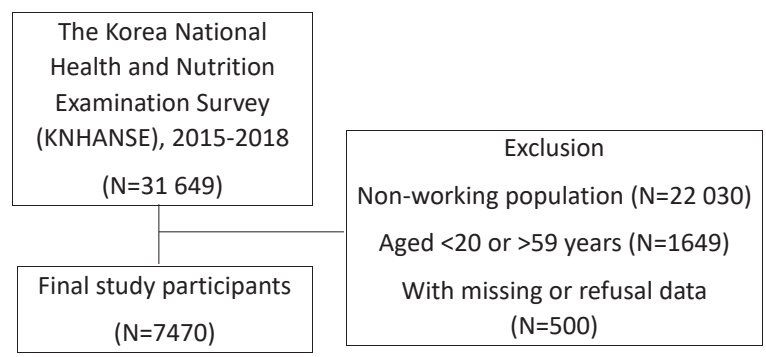

Figure 1. Participant inclusion flowchart.

schedule identified with the question "Do you mainly work weekly (06:00-18:00 hours)? Or do you work during other time slots?" An answer other than "daytime fixed working schedule (06:00-18:00 hours)" indicated a shift-work schedule. The shift-work schedule included evening (14:00-24:00 hours) work, night-time (21:00-08:00 hours) work, 24-hour shift, and split or irregular shifts.

Working hours were based on the total number of hours worked per week ascertained from the selfreported questionnaire that included the following question: "on average, excluding meal times, how many hours do you work at your job per week including overtime?"

The definitions of working schedules and long working hours reflect social, cultural, or economic circumstances and are changeable. We defined long working hours on the basis of the Korean labor standards and descriptions in previous studies. The Labor Standard Act in Korea allows weekly working hours of up to 52 hours, although the weekly working hours can be extended with the agreement of all parties (21). Previous studies from Korea indicated that if the work hours per week exceed 52 hours, the risk of illness because of long working hours increased $(22,23)$. Thus, we dichotomously categorized work hours into two groups on the basis of the responses "No" and "Yes" to long working hours (weekly work hours $\leq 52$ and $>52$, respectively).

\section{High-sensitivity C-reactive protein}

The hsCRP level was determined from blood samples collected in 3-mL ethylenediaminetetraacetic acidcoated tubes (BD Vacutainer, Franklin Lakes, NJ, USA), stored at $2-8^{\circ} \mathrm{C}$ in refrigerated containers, and analyzed within 24 hours of sample collection. The hsCRP level was measured using an immunoturbidimetric method (Cobas, Roche, Germany). Human CRP agglutinates with latex particles coated with monoclonal anti-CRP antibodies, and the aggregates obtained were quantified turbidimetrically. The Food and Drug Administration has approved this method for clinical use in Korea and 
other developed countries $(24,25)$. In this study, the participants were categorized into three groups based on the hsCRP level in accordance with the criteria of the American Heart Association and Centers for Disease Control and Prevention: normal $<1.0$; moderately increased 1.0-3.0; and highly increased $>3.0 \mathrm{mg} / \mathrm{L}$ (26).

\section{Other covariates}

We used age, sex, educational status. and household income level as socioeconomic variables. The educational level was stratified into three levels: graduate to middle school, high school, and college or higher. The household income level was categorized by quartiles [lowest (quartile 1) to highest (quartile 4)] based on the yearly household income level. Past smoking indicated smokers who had stopped tobacco smoking for $\geq 1$ month. Individuals who had smoked $<100$ cigarettes in their lifetime were placed in the "none" category. Moderate alcohol drinking for women and men was defined as the consumption of $<5$ and $<7$ glasses of alcohol $\leq 2$ times per week, respectively. Severe alcohol drinking was classified as the consumption of more than the moderate alcohol intake level. Metabolic syndrome was diagnosed according to the recommendations of the International Diabetes Federation (27) and was defined as the presence of $\geq 3$ of the following 5 abnormalities: (i) central obesity (waist circumference $>90 \mathrm{~cm}$ among men or $>80 \mathrm{~cm}$ among women); (ii) hypertension (blood pressure $\geq 130 / 85 \mathrm{mmHg}$ or antihypertensive drug treatment); (iii) hyperglycemia (fasting glucose level of serum $\geq 100 \mathrm{mg} / \mathrm{dL}$ or use of antidiabetic medication); (iv) high triglyceride (TG) levels ( $\mathrm{TG} \geq 150 \mathrm{mg} / \mathrm{dL}$ or drug treatment for dyslipidemia); or (v) low high-density lipoprotein cholesterol (HDL-C) levels $(<40 \mathrm{mg} / \mathrm{dL}$ among men and $<50 \mathrm{mg} / \mathrm{dL}$ among women).

\section{Statistical analysis}

The differences in general characteristics according to shift work or long work hours were calculated for each variable using the chi-square test. Odds ratios (OR) and $95 \%$ confidence intervals (CI) were calculated using logistic regression models to evaluate the association between the hsCRP level and shift work or long work hours with sex and age group stratification. We calculated the age-standardized prevalence ratio of abnormal hsCRP (>1.0 mg/L) according to work conditions with reference to the same-aged general population in the KNHANES. The interaction effect between shift work and long work hours on hsCRP level was estimated with the P-value. In subgroup analysis with sex and age stratification, an interaction effect was demonstrated based on the P-value, and a relative excess risk due to interaction (RERI) and attributable proportion (AP) were represented by the $95 \%$ CI. All of the interaction effects were estimated with "no long work hours" and "no shift work" group as a reference. All statistical analyses were performed using SAS (version 9.4; SAS Institute, Cary, NC, USA). Two-tailed P-values $<0.05$ were considered statistically significant.

\section{Results}

The baseline characteristics according to hsCRP levels are presented in table 1 . The prevalence of extremely high and moderately high hsCRP levels was higher among men than women. A lower household income level was significantly associated with a higher prevalence of increased hsCRP levels. Current smokers and participants with metabolic syndrome showed significantly higher prevalence of increased hsCRP levels. The long work hours group also had a higher prevalence of increased hsCRP levels.

Table 1. Participant characteristics according to high-sensitivity Creactive protein (hsCRP) levels. [MetS=metabolic syndrome.]

\begin{tabular}{|c|c|c|c|c|c|}
\hline \multirow[t]{3}{*}{ Characteristics } & \multirow{2}{*}{$\begin{array}{c}\text { Total } \\
\text { participants }\end{array}$} & \multicolumn{3}{|c|}{ hsCRP (mg/L) } & \multirow[t]{2}{*}{ P-value } \\
\hline & & $\begin{array}{c}\text { Normal } \\
(<1.0)\end{array}$ & $\begin{array}{c}\text { Moderately } \\
\text { increased } \\
(1.0-3.0)\end{array}$ & $\begin{array}{l}\text { Highly } \\
\text { increased } \\
(>3.0)\end{array}$ & \\
\hline & $\mathrm{N}(\%)$ & $\mathrm{N}(\%)$ & $\mathrm{N}(\%)$ & $\mathrm{N}(\%)$ & \\
\hline Overall & 7470 & 5581 & 1397 & 492 & \\
\hline & & & & & $<0.000$ \\
\hline Men & 3774 (50.5) & $2687(71.1)$ & 806 (21.4) & $281(7.5)$ & \\
\hline Women & 3696 (49.5) & $2894(78.3)$ & $591(16.0)$ & $211(5.7)$ & \\
\hline Age (years) & & & & & 0.7118 \\
\hline $20-39$ & 3176 (42.5) & $2389(75.2)$ & $571(18.0)$ & $216(6.8)$ & \\
\hline $40-59$ & 4294 & $3192(74$ & & & \\
\hline Education level & & & & & 0.3780 \\
\hline Middle & $595(8.0)$ & 430 (72.3) & & $33(5.5)$ & \\
\hline High s & 2858 & 211 & & 184 & \\
\hline$\geq$ College & $4017(53.7)$ & 3032 (75.5) & 710 (17.7) & $275(6.8)$ & \\
\hline $\begin{array}{l}\text { Household } \\
\text { income (quartile }\end{array}$ & & & & & $<0.0001$ \\
\hline $1^{\text {st }}$ & $432(5.7)$ & 314 (72.7) & $85(19.7)$ & $33(7.6)$ & \\
\hline $2^{\text {nd }}$ & $1538(20.6)$ & 109 & & & \\
\hline $3^{\text {rd }}$ & 9) & $188 \mathrm{c}$ & & & \\
\hline $4^{\text {th }}$ & 2970 (39.8) & $2281(76.8)$ & 514 (17.3) & $175(5.9)$ & \\
\hline Smoking & & & & & $<0.0001$ \\
\hline None & $4270(57.2)$ & 3307 (77.5) & & & \\
\hline & 6) & 106 & & & \\
\hline Current & 1739 (23.2) & $1213(69.8)$ & 388 (22.3) & $138(7.9)$ & \\
\hline Drinking & & & & & 0.3420 \\
\hline None & $1090(14.6)$ & & & 78 (7.2) & \\
\hline Moder & $5266 i$ & 3982 & & 331 & \\
\hline Severe & 1114 (14.9) & 797 (71.5) & $234(21.0)$ & $83(7.5)$ & \\
\hline MetS & & & & & $<0.000$ \\
\hline No & $6020(80.6)$ & 4766 (79.2) & & $329(5.4)$ & \\
\hline Yes & 1450 (19.4) & 815 (56.2) & 472 (32.6) & $163(11.2)$ & \\
\hline Shift work & & & & & 0.3973 \\
\hline No & 6205 (ع & $4627(72.6)$ & 1162 & & \\
\hline Yes & 1265 & 954 (75.4) & 235 (18.6) & $76(6.0)$ & \\
\hline Long work hours & & & & & 0.0004 \\
\hline No & 6314 (84.5) & 4770 (75.5) & 1141 (18.1) & $403(6.4)$ & \\
\hline Yes & 1156 (15.5) & 811 (70.2) & $256(22.1)$ & $89(7.7)$ & \\
\hline
\end{tabular}


Table 2 presents the results of the logistic regression analysis for the risk of increased hsCRP levels with respect to shift work or long work hours based on sex and age group stratification. Significantly elevated risks of moderately and highly increased hsCRP levels were identified among men in the long work hours group after adjustments for age, educational level, income level, smoking, alcohol consumption, and metabolic syndrome [OR 1.21 (95\% CI 1.02-1.44) and OR 1.33

Table 2. Association between high-sensitivity C-reactive protein (hsCRP) level and working condition on the logistic regression analyses. All models are adjusted for age, educational level, income level, smoking, alcohol consumption, and metabolic syndrome. Numbers in bold indicate statistical significance. [OR=odds ratio; $95 \% \mathrm{Cl}=95 \%$ confidence interval]

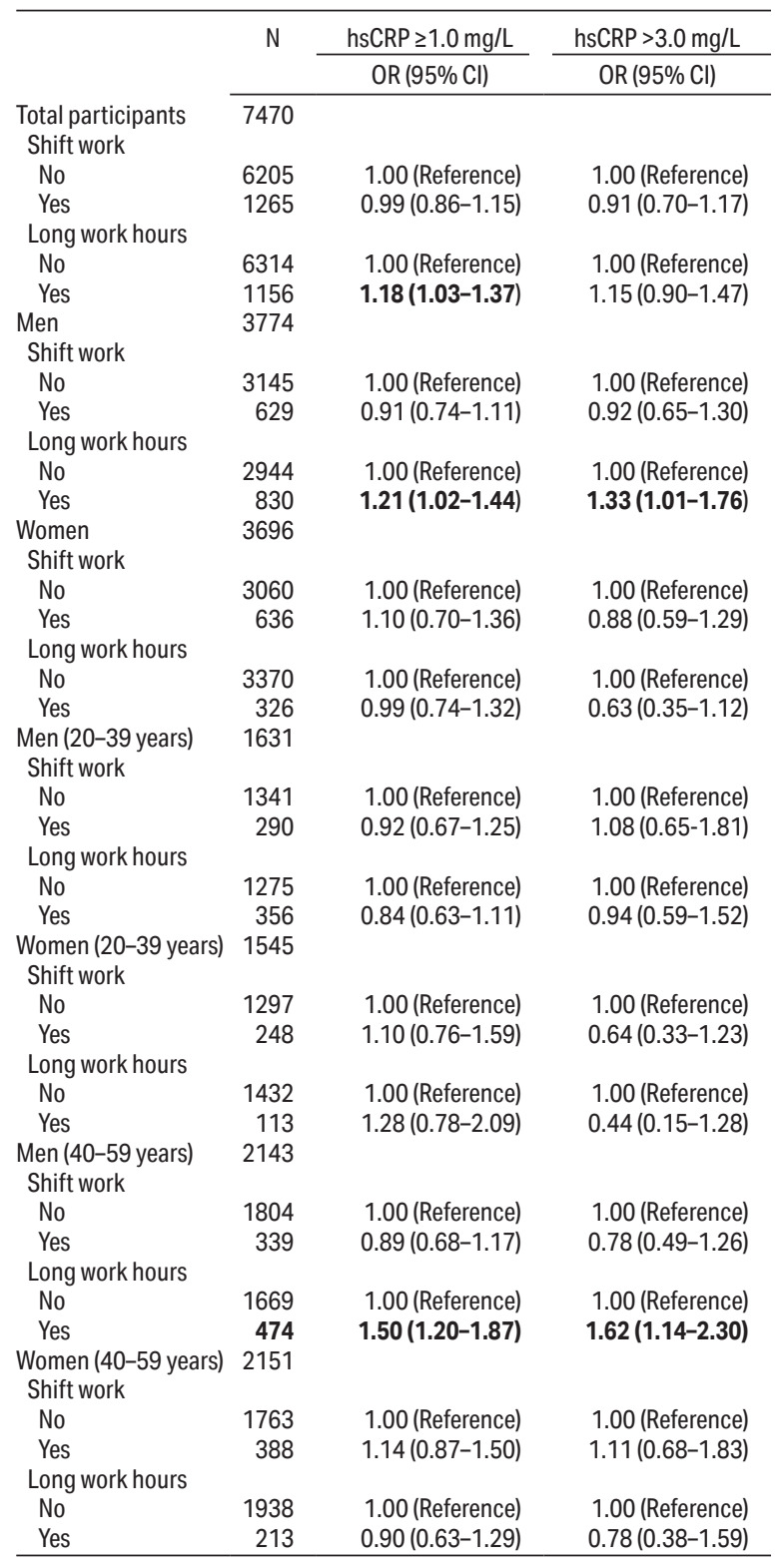

(95\% CI 1.01-1.76), respectively]. After sex and age group stratification, the association between long work hours and increased hsCRP levels was enhanced among middle-aged men [ $40-59$ years: OR $1.50(95 \%$ CI 1.20 1.87 ) and OR 1.62 (95\% CI 1.14-2.30), respectively]. However, there was no significant association between shift work and increased hsCRP levels.

Table 3 presents the results of the interaction effect of long working hours and shift work on the risk of increased hsCRP levels $(\geq 1.0 \mathrm{mg} / \mathrm{L})$. Overall, there was no interaction between long working hours and shift work with the hsCRP level ( $\mathrm{P}$-value for interaction $=0.1648)$. After sexspecific stratification, the strata with only women showed a statistically significant interaction effect on increased hsCRP levels $(\mathrm{P}$-value for interaction $=0.0001)$.

Figure 2 shows the results of the interaction analysis of long work hours with shift work and the influence on higher hsCRP level with regard to sex and age group stratification. There was an interaction effect between long work hours and shift work on increased hsCRP levels among middle-aged men and women. The RERI were 0.03 (95\% CI $0.02-0.04)$ and $0.56(95 \%$ CI $0.45-0.68)$ among middle-aged men and women, respectively. The AP were 0.02 (95\% CI $0.01-0.03$ ) and $0.36(95 \%$ CI $0.31-0.40)$ among middle-aged men and women, respectively. However, only middle-aged women showed a statistically significant result (P-value for interaction $=0.0365$ )

\section{Discussion}

This study investigated the association of work conditions, such as long work hours and shift work, with the hsCRP level, which was considered a systematic proinflammatory factor. Male workers with long work

Table 3. Interaction effect of long work hours and shift work on elevated high-sensitivity C-reactive protein level (hsCRP $\geq 1.0 \mathrm{mg} / \mathrm{L}$ ) [SPR=age-standardized prevalence ratio; $\mathrm{Cl}=$ confidence interval]

\begin{tabular}{|c|c|c|c|}
\hline & \multicolumn{2}{|c|}{ Long work hours } & \multirow{2}{*}{$\begin{array}{l}\text { P-value for } \\
\text { interaction }\end{array}$} \\
\hline & No, SPR (95\% Cl) & Yes, SPR (95\% Cl) & \\
\hline \multicolumn{3}{|l|}{$\begin{array}{l}\text { Total participants } \\
\text { Shift work }\end{array}$} & 0.1648 \\
\hline No & $1.00(0.95-1.06)$ & $1.24(1.10-1.38)$ & \\
\hline Yes & $0.98(0.85-1.11)$ & $1.21(0.91-1.51)$ & \\
\hline Men & & & 0.9584 \\
\hline \multicolumn{4}{|l|}{ Shift work } \\
\hline No & $1.03(0.95-1.10)$ & $1.21(1.05-1.37)$ & \\
\hline Yes & $0.95(0.77-1.13)$ & $1.05(0.75-1.35)$ & \\
\hline Women & & & 0.0001 \\
\hline \multicolumn{4}{|l|}{ Shift work } \\
\hline No & $0.96(0.88-1.04)$ & $1.01(0.75-1.26)$ & \\
\hline Yes & $1.02(0.83-1.20)$ & $1.38(0.70-2.05)$ & \\
\hline
\end{tabular}



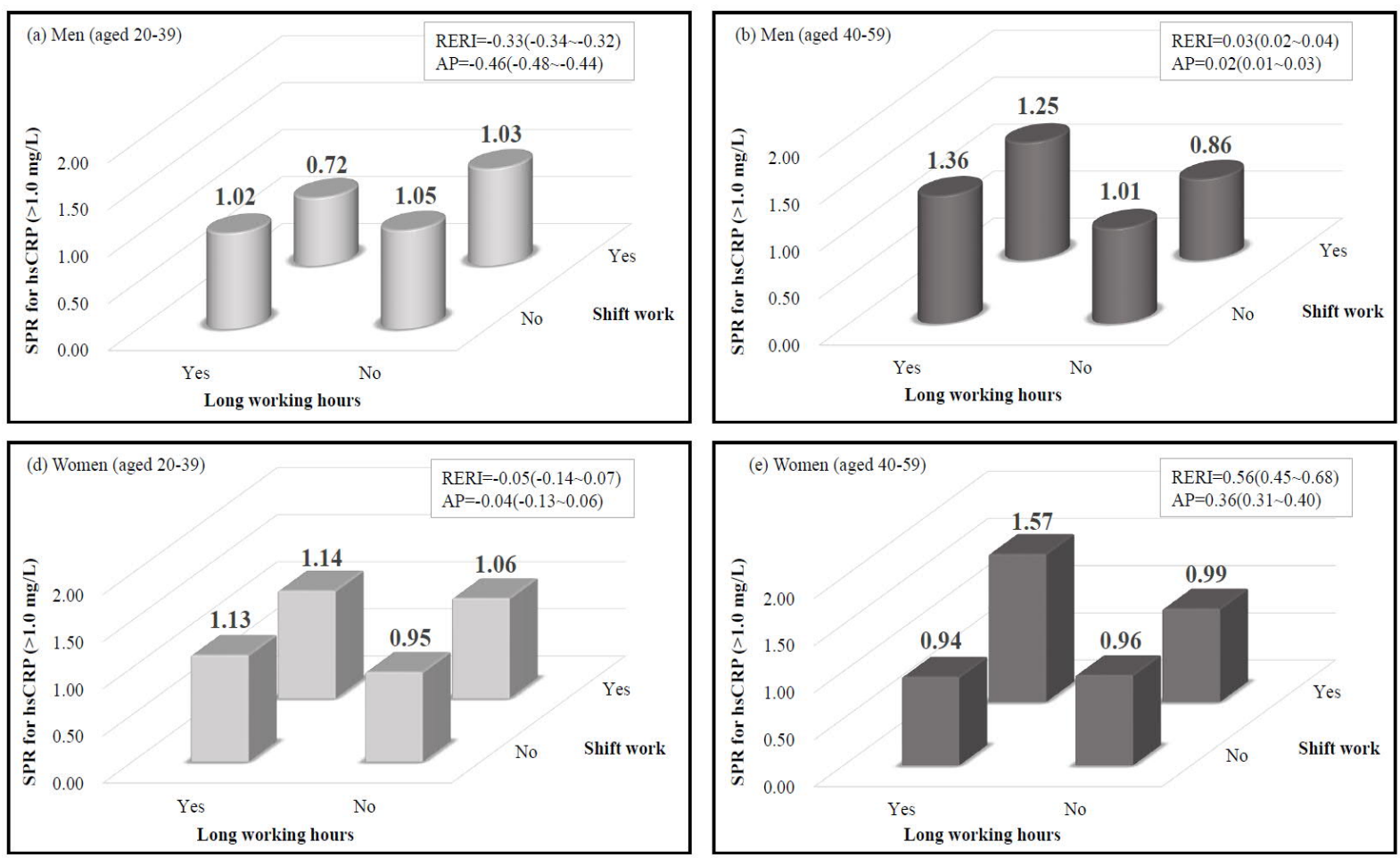

Figure 2. Results of interaction analysis of long work hours and shift work on increased high-sensitivity C-reactive protein (hsCRP) level with sex and age group stratification. Interaction effects were estimated with respect to no long work hours and no shift work group as a reference. [SPR=age-standardized prevalence ratio; RERI=relative excess risk due to interaction with $95 \%$ confidence interval; $\mathrm{AP}=$ attributable proportion with $95 \%$ confidence interval].

hours had a higher likelihood of increased hsCRP levels. Despite the attenuation of the relationship between the risk of increased hsCRP levels and shift-work schedule after controlling for confounders, we found a significant interaction for an increased prevalence of elevated hsCRP levels between long work hours and the shift work schedule, especially among the middle-aged working population.

We found that long work hours were associated with elevated hsCRP levels, consistent with the findings of previous studies that showed a close association between long work hours and elevated hsCRP levels, especially among older workers (28). Long work hours could lead to sleep disturbance that is, in turn, directly associated to a lack of time for physical and neuropsychiatric recovery $(21,29)$. Previous studies have indicated that sleep disturbance is associated with increased levels of markers of systemic inflammation, including hsCRP (30). Extended work hours could activate the stress-response system that would influence the hypothalamic-pituitaryadrenal axis to increase the levels of glucocorticoids, which is considered a response to increased systematic inflammation (31). Moreover, a higher prevalence of smoking, obesity, and other adverse behaviors has been reported in those who work long hours (32).

A recent study showed that shift work influenced some immunological biomarkers (33). Thus, we hypothesized that hsCRP is also associated with shift work; however, we found no significant association between shift work and elevated hsCRP levels. This finding is inconsistent with that of an earlier report (34). However, the interaction between long work hours and shift work and elevated hsCRP levels was statistically significant. This result is consistent with previous studies that reported that the association between shift work and elevated inflammatory indices is markedly evident among those with long work hours or those working in prolonged shifts $(35,36)$. Zeler et al $(35)$ investigated the oxidative and inflammatory status according to physical workloads of employees. They found that the levels of various inflammatory markers, including total peroxides, total antioxidant capacity, adrenocorticotropic hormone, oxidative stress index, and hsCRP, were significantly higher among heavy workers (slaughterhouse employees) than among office workers, especially those who worked longer hours (ie, 12- versus 8-hour shifts).

Buyukhatipoglu et al (36) also reported increased oxidative stress indices after prolonged work hours among healthcare workers who were on 24-hour on-call shifts compared with non-healthcare staff who worked 8-hour shifts. Thus, the hypothesis that both long work hours and shift work are more likely to induce systemic 
inflammation with an interaction effect, as shown in this study, seems feasible. A plausible explanation for this is the alterations in circadian rhythms that exacerbate chronic systemic inflammation by triggering proinflammatory activation of macrophages and inflammatory signaling pathways (37).

It remains unclear why the interaction effect was only significant among women, although sex differences in the circadian system may be a possible explanation. Duffy et al (38) reported that the intrinsic circadian period was shorter among women than men, and a greater proportion of women had intrinsic circadian periods $<24$ hours (38). This shorter intrinsic circadian period leads to circadian misalignment associated with alteration in physiologic processes, including elevated levels of markers of systemic inflammation. Wright et al (39) observed significantly increased CRP levels in the circadian misalignment group and decreased CRP levels in the synchronized group after weeks of circadian entrainment.

There may be another possible explanation considering the difference in total working hours between men and women. The total working hours of women may be longer than those of men because women do more domestic labor. The Statistics Korea 2019 nationwide Time Use Survey showed that men (husbands) of dualincome households spent 8 hours and 46 minutes for inevitable daily activities, including 5 hours and 50 minutes for work and 54 minutes for domestic labor, whereas women (wives) of dual-income households spent 9 hours and 24 minutes for inevitable daily activities, including 4 hours and 37 minutes for work and 3 hours and 7 minutes for domestic labor (40). Men and women in single-income households spent very similar time for inevitable daily activities compared with those in dual-income households. Although only average statistics are available and such statistics cannot be directly linked to this study data, women apparently do more domestic labor than men, even when they have a job. Women who work long hours with shift work may have less time for rest than men with the same work characteristics because women do more housework. This may be one of the possible explanations why the interaction effect between long work hours and shift work on the increase of hsCRP levels was found only among women.

Given the nature of chronic diseases, one of the best approaches to prevent CVD is primary prevention. Emphasis should be placed on controlling risk factors and reducing unsafe behaviors and conditions to prevent CVD. From this viewpoint, reducing work hours or maintaining an appropriate level of work hours for young and middle-aged workers may be helpful to reduce the risk of diseases that occur due to chronic inflammation. Special attention should be focused on shift workers to emphasize the need to control other risk factors for the prevention of diseases when shift work is inevitable.

The present work contributes to the existing knowledge base of the association between work conditions and inflammation by providing an interaction analysis with sex- and age group-stratified analysis that was adjusted for confounders. In support of the evidence from previous studies that were conducted with relatively small sample sizes, we report a significant association between long work hours and shift work and increased hsCRP levels in a large representative sample of Korean workers.

This study had some limitations, the major being its cross-sectional design. This made it difficult to determine a causality association between work conditions and hsCRP. Further longitudinal studies are required to ascertain the causality in this regard. Moreover, we could not describe other work condition-related factors of inflammation besides the work hours and working schedule due to a lack of information about workplace hazardous factors in the KNHANES. Systematic inflammation could have been increased because of exposure to various hazardous factors such as organic chemicals, dust, or stress at the workplace. The findings of this present work cannot be extrapolated to all work conditions in the general population. We could not describe the duration of career or the duration of exposure to shift work schedule or long work hours associated to the level of hsCRP because of the lack of information on these aspects in the KNHANES. Further studies are needed to identify the dose-response relationship between shift work or long work hours and the risk of elevated hsCRP levels.

In conclusion, long work hours were significantly associated with increased hsCRP levels among middleaged men. Shift work itself was not a risk factor for low-grade inflammation. However, there was a significant interaction effect between long work hours and shift work on low-grade inflammation, especially among middle-aged women. Overall, working hours were related to low-grade inflammatory processes, but only among middle-aged workers.

\section{Acknowledgment}

This research was supported by a National Research Foundation of Korea (NRF) grant funded by the Korean Government, Ministry of Science and ICT (grant number NRF-2017R1C1B5076698). The funder had no role in the design of the study; in the collection, analyses, or interpretation of data; in the writing of the manuscript or in the decision to publish the results. 


\section{Conflicts of interest}

The authors declare no conflicts of interest.

\section{References}

1. Furman D, Campisi J, Verdin E, Carrera-Bastos P, Targ S, Franceschi C, et al. Chronic inflammation in the etiology of disease across the life span. Nat Med. 2019;25(12):1822-32. https://doi.org/10.1038/s41591-019-0675-0.

2. Lu XT, Zhao YX, Zhang Y, Jiang F. Psychological stress, vascular inflammation, and atherogenesis: potential roles of circulating cytokines. J Cardiovasc Pharmacol. 2013;62(1):612. https://doi.org/10.1097/FJC.0b013e3182858fac.

3. Wu N, Xu B, Xiang Y, Wu L, Zhang Y, Ma X, et al. Association of inflammatory factors with occurrence and recurrence of atrial fibrillation: a meta-analysis. Int J Cardiol. 2013;169(1):62-72. https://doi.org/10.1016/j.ijcard.2013.08.078.

4. Anrather J, Iadecola C. Inflammation and Stroke: An Overview. Neurotherapeutics. 2016;13(4):661-70. https://doi. org/10.1007/s13311-016-0483-x.

5. Rana A, Musto AE. The role of inflammation in the development of epilepsy. J Neuroinflammation. 2018;15(1):144. https://doi. org/10.1186/s12974-018-1192-7.

6. Ross R. Atherosclerosis--an inflammatory disease. N Engl J Med. 1999;340(2):115-26. https://doi.org/10.1056/ NEJM199901143400207.

7. Bassuk SS, Rifai N, Ridker PM. High-sensitivity C-reactive protein: clinical importance. Curr Probl Cardiol. 2004;29(8):439 93. https://doi.org/10.1016/S0146-2806(04)00074-X.

8. Martinez BK, White CM. The Emerging Role of Inflammation in Cardiovascular Disease. Ann Pharmacother. 2018;52(8):8019. https://doi.org/10.1177/1060028018765939.

9. Zhou Y, Han W, Gong D, Man C, Fan Y. Hs-CRP in stroke: A meta-analysis. Clin Chim Acta. 2016;453:21-7. https://doi. org/10.1016/j.cca.2015.11.027.

10. Costa G. Shift work and health: current problems and preventive actions. Saf Health Work. 2010;1(2):112-23. https://doi.org/10.5491/SHAW.2010.1.2.112.

11. Park S, Lee JH, Lee W. The Effects of Workplace Rest Breaks on Health Problems Related to Long Working Hours and Shift Work among Male Apartment Janitors in Korea. Saf Health Work. 2019;10(4):512-7. https://doi.org/10.1016/j. shaw.2019.10.003.

12. Leproult R, Holmback U, Van Canter E. Circadian Misalignment Augments Markers of Insulin Resistance and Inflammation, Independently of Sleep Loss. Diabetes. 2014;63(6):1860-9. https://doi.org/10.2337/db13-1546.

13. McDade TW. Early environments and the ecology of inflammation. Proc Natl Acad Sci U S A. 2012;109 Suppl 2:17281-8. https://doi.org/10.1073/pnas.1202244109.

14. Yan Q. Stress and Systemic Inflammation: Yin-Yang Dynamics in Health and Diseases. Methods Mol Biol. 2018;1781:3-20. https://doi.org/10.1007/978-1-4939-7828-1_1.

15. Virtanen M, Kivimaki M. Long Working Hours and Risk of Cardiovascular Disease. Curr Cardiol Rep. 2018;20(11):123. https://doi.org/10.1007/s11886-018-1049-9.

16. Puttonen S, Harma M, Hublin C. Shift work and cardiovascular disease - pathways from circadian stress to morbidity. Scand J Work Environ Health. 2010;36(2):96-108. https://doi. org/10.5271/sjweh.2894.

17. Puttonen S, Viitasalo K, Harma M. Effect of shiftwork on systemic markers of inflammation. Chronobiol Int. 2011;28(6):528-35. https://doi.org/10.3109/07420528.2011 .580869 .

18. Kwak HS, Park HO, Kim YO, Son JS, Kim CW, Lee JH, et al. The effect of shift work on high sensitivity C-reactive protein level among female workers. Ann Occup Environ Med. 2019;31:e5. https://doi.org/10.35371/aoem.2019.31.e5.

19. Lee DH, Kang SK, Choi WJ, Kwak KM, Kang D, Lee SH, et al. Association between serum ferritin and hypertension according to the working type in Korean men: the fifth Korean National Health and nutrition examination survey 20102012. Ann Occup Environ Med. 2018;30:40. https://doi. org/10.1186/s40557-018-0251-y.

20. Kweon S, Kim Y, Jang MJ, Kim Y, Kim K, Choi S, et al. Data resource profile: the Korea National Health and Nutrition Examination Survey (KNHANES). Int J Epidemiol. 2014;43(1):69-77. https://doi.org/10.1093/ije/dyt228.

21. Lee W, Lim SS, Kim B, Won JU, Roh J, Yoon JH. Relationship between long working hours and periodontitis among the Korean workers. Sci Rep. 2017;7(1):7967. https://doi. org/10.1038/s41598-017-08034-6.

22. Ok G, Ahn J, Lee W. Association between irregular menstrual cycles and occupational characteristics among female workers in Korea. Maturitas. 2019;129:62-7. https://doi. org/10.1016/j.maturitas.2019.07.019.

23. Yoon JH, Jung PK, Roh J, Seok H, Won JU. Relationship between Long Working Hours and Suicidal Thoughts: Nationwide Data from the 4th and 5th Korean National Health and Nutrition Examination Survey. PLoS One. 2015;10(6):e0129142. https:// doi.org/10.1371/journal.pone.0129142.

24. Jung YE, Kang KY. Elevated hs-CRP level is associated with depression in younger adults: Results from the Korean National Health and Nutrition Examination Survey (KNHANES 2016). Psychoneuroendocrinology. 2019;109:104397. https://doi. org/10.1016/j.psyneuen.2019.104397.

25. Lolekha PH, Chittamma A, Roberts WL, Sritara P, Cheepudomwit S, Suriyawongpaisal P. Comparative study of two automated high-sensitivity C-reactive protein methods in a large population. Clin Biochem. 2005;38(1):31-5. https://doi. org/10.1016/j.clinbiochem.2004.09.001.

26. Pearson TA, Mensah GA, Alexander RW, Anderson JL, Cannon RO, 3rd, Criqui M, et al. Markers of inflammation and cardiovascular disease: application to clinical and public health practice: A statement for healthcare professionals from the Centers for Disease Control and Prevention and the American Heart Association. Circulation. 2003;107(3):499-511. https:// doi.org/10.1161/01.CIR.0000052939.59093.45. 
27. Alberti KG, Zimmet P, Shaw J. Metabolic syndrome--a new world-wide definition. A Consensus Statement from the International Diabetes Federation. Diabet Med. 2006;23(5):46980. https://doi.org/10.1111/j.1464-5491.2006.01858.x.

28. Lee J, Kim HR. The Association Between Long Working Hours and High-Sensitivity C-Reactive Protein in Older Aged Individuals: The Korea National Health and Nutrition Examination Survey (KNHANES) 2015. J Occup Environ Med. 2018;60(9):775-80. https://doi.org/10.1097/ JOM.0000000000001359.

29. Kecklund G, Axelsson J. Health consequences of shift work and insufficient sleep. BMJ. 2016;355:i5210. https://doi. org/10.1136/bmj.i5210.

30. Irwin MR, Olmstead R, Carroll JE. Sleep Disturbance, Sleep Duration, and Inflammation: A Systematic Review and Meta-Analysis of Cohort Studies and Experimental Sleep Deprivation. Biol Psychiatry. 2016;80(1):40-52. https://doi. org/10.1016/j.biopsych.2015.05.014.

31. Penz M, Siegrist J, Wekenborg MK, Rothe N, Walther A, Kirschbaum C. Effort-reward imbalance at work is associated with hair cortisol concentrations: Prospective evidence from the Dresden Burnout Study. Psychoneuroendocrinology. 2019;109:104399. https://doi.org/10.1016/j.psyneuen.2019.104399.

32. Artazcoz L, Cortes I, Escriba-Aguir V, Cascant L, Villegas R. Understanding the relationship of long working hours with health status and health-related behaviours. J Epidemiol Community Health. 2009;63(7):521-7. https://doi. org/10.1136/jech.2008.082123.

33. Bjorvatn B, Axelsson J, Pallesen S, Waage S, Vedaa Ø, Blytt KM, et al. The Association Between Shift Work and Immunological Biomarkers in Nurses. Frontiers in Public Health. 2020;8:415. https://doi.org/10.3389/ fpubh.2020.00415.
34. Morris CJ, Purvis TE, Mistretta J, Hu K, Scheer F. Circadian Misalignment Increases C-Reactive Protein and Blood Pressure in Chronic Shift Workers. J Biol Rhythms. 2017;32(2):154-64. https://doi.org/10.1177/0748730417697537.

35. Zelzer S, Tatzber F, Herrmann M, Wonisch W, Rinnerhofer $\mathrm{S}$, Kundi M, et al. Work Intensity, Low-Grade Inflammation, and Oxidative Status: A Comparison between Office and Slaughterhouse Workers. Oxid Med Cell Longev. 2018;2018: https://doi.org/10.1155/2018/2737563.

36. Buyukhatipoglu H, Kirhan I, Vural M, Taskin A, Sezen Y, Dag $\mathrm{OF}$, et al. Oxidative stress increased in healthcare workers working 24-hour on-call shifts. Am J Med Sci. 2010;340(6):4627. https://doi.org/10.1097/MAJ.0b013e3181ef3c09.

37. Kim SM, Neuendorff N, Alaniz RC, Sun Y, Chapkin RS, Earnest DJ. Shift work cycle-induced alterations of circadian rhythms potentiate the effects of high-fat diet on inflammation and metabolism. FASEB J. 2018;32(6):3085-95. https://doi. org/10.1096/fj.201700784R.

38. Duffy JF, Cain SW, Chang AM, Phillips AJ, Munch MY, Gronfier $\mathrm{C}$, et al. Sex difference in the near-24-hour intrinsic period of the human circadian timing system. Proc Natl Acad Sci U S A. 2011;108 Suppl 3:15602-8. https://doi. org/10.1073/pnas.1010666108.

39. Wright KP, Jr., Drake AL, Frey DJ, Fleshner M, Desouza CA, Gronfier $\mathrm{C}$, et al. Influence of sleep deprivation and circadian misalignment on cortisol, inflammatory markers, and cytokine balance. Brain Behav Immun. 2015;47:24-34. https://doi. org/10.1016/j.bbi.2015.01.004.

40. KOSIS. Time Use Survey. 2019. Statistics Korea, [cited Sep 30, 2020]. Available from: https://kosis.kr.

Received for publication: 8 June 2020 